\title{
Architectural Drawings: Teaching and Understanding a Visual Discipline
}

Peter Schmid

Editorial Summary: Professional drawing has always played an important role in the training of architects. Plan-drawings have already been sufficiently considered in established architectural research. The research of Peter Schmid presented in this text focuses on so far only scarcely examined architectural sketchbooks as well as various records used for architectural education, such as manuscripts for lectures or notes on perspective theory which belong to the »Munich School « - a tradition of teaching hand-drawing that developed over a period of 150 years through an on-going teacher-student relationship at the Technical University of Munich. He finds that the aim of »Munich School« was not only learning how to illustrate, but also to comprehend architecture through graphic analysis - thereby combining teaching and practice. Against the background that the interest in hand-drawings has significantly increased in recent years, the research helps to refine the role of hand-drawings today as a tool that sets "processes of cognition in motion «. [Ferdinand Ludwig]

Keywords: Sketchbook; Freehand Drawing; Architectural Education; »Münchner Zeichenschule«; Architecture Projection; Perspective Drawing; Analytical Drawing; Friedrich von Thiersch; Hans Döllgast.

\section{The Architectural Drawing as a Profession-Specific "Know-How"}

Rem Koolhaas recently put forward the thesis that contemporary architects still work in the same way today as they did during the Renaissance (Michaelsen 2018). A provocative claim, which could immediately be countered by the ease of work and tools provided by the rapidly advancing technical achievements of the digital turn. Koolhaas, however, does not refer to the external circumstances of the working world, but to a certain aspect of designing architecture, which he calls the thinking of »beauty«. Indeed, it seems difficult to imagine that the use of digital tools or the application of Building Information Modeling (BIM) alone is a guarantee of »beauty« in 
architectural design. Koolhaas alludes to the theories that have described the thought processes amidst the emergence of architecture since early modern times. In the Renaissance, with the disegno-theories, architects established a body of thought on architectural design in which drawing - or the ability to sketch - was attributed an essential role. The architects of the Renaissance, above all Giorgio Vasari, viewed drawing as a space of possibility which served the creative architect to successively materialize an initially vague idea in a line graphic in order to be able to judge the basic idea - concetto and to finally transform it into perfect beauty according to the rules of art (Vasari 2012: 98). ${ }^{1}$ In fact, the sketch, along with the model, is still a tool that is used today in connection with serious architectural design. Regardless of the external form, whether analogue or digital, the ability to sketch spatial situations is a fundamental requirement for creative work in architecture. The processes that take place during the development of spatial ideas in drawings are procedures which, in the case of practicing architects, mature into schematic experiences, or, in other words, into a "procedure know-how« that is difficult for outsiders to understand or comprehend.

Conversely, it is therefore a logical conclusion that this »know-how the part of the insiders is also a basic prerequisite for the scientific description and processing of sketches and architectural drawings. In all scientific disciplines, the direct professional affiliation of the researchers is of course relevant. Even interdisciplinary research projects pursue the method of only one specialist science as a common basis and formulate only one research question which is tailored to the needs of the discipline and whose results are important not only from the point of view of the researcher but above all for the practical user.

In the field of architecture, an important part of the research has long been undertaken by art and architectural historians. This highly specialized discipline is devoted exclusively to research. Other than the architects themselves, art historians take an outside perspective and observe the work of practical architects from a distance. Thereby, they aim to make their research as objective as possible in the first place. The perspective of

1 In chapter 15 of Vasari's Book On Painting the disegno ist described as: »And since from this knowledge a certain idea and judgement emerges, which in the mind forms the thing that is later designed by hand and then called a drawing, one may conclude that disegno is nothing different than a descriptive imagination, which shows the initially vague idea, that was formed by thoughts, and finally appears as a visible idea« (Vasari 2012 [1550]: 98). 
the designing and practicing architect is therefore often lacking - especially in historic reseach. In this respect, art history follows a purely theoretical method, which is based on the scientific understanding of the subject. In simple terms, the questions develop from previous theoretical constructs of thought or theses, which are plausibly substantiated or refuted with the help of archival or textual sources. The highest goal to be achieved is therefore not a definitive statement from the outset, but plausibly argued theories. Although the schism of architectural research and architectural practice undisputedly leads to professional specialization and optimization on both sides, it also obviously requires a constant exchange between the two related disciplines.

\section{Research Field of Architectural Education}

In the particular thematic area concerning the subject of sketching or architectural drawing, art history has developed into an independent field of research, hitherto it remains largely closed to architects. Normally, the research culminates in classical catalogues raisonnés on an architect or a group. However, the subject of drawing lessons and even the elaboration of processual sequences during the creation of a drawing are also undertaken within these research projects. The increasing interest in strategies for teaching drawing from the side of art history and art studies has led to numerous survey works in recent years, which have been produced at the University of Hamburg and the Central Institute of Art History in Munich. They do not exclusively pursue a study of history, but also use the knowledge of the observed teaching methods to discuss controversial current concepts and pose questions for the future.

What remains unanswered, however, are the questions regarding the significance of the research efforts for contemporary architecture, or of the transfer of the results into current architectural practice.

For the scientific examination of the drawing theory of the so-called »Munich School«, the question concerning the current possibilities of using the research results for current teaching was decisive from the very beginning and prioritized the question of the methodological approach. The research was directed at educational strategies for teaching the arts at the Technical University in Munich over a period of 150 years ending with the present day. 
The Munich lessons in architectural drawing are directly related to the name of its most famous representative, Hans Döllgast, ${ }^{2}$ whose freehand-drawings have a high recognition value due to his distinct personal handwriting. Döllgast's teaching, in conjunction with his special style, resulted in the drawing method first being known as the »Munich School", which already received national attention during his lifetime. He also developed a simple and very instructive teaching method for linear drawing in his lessons, which he presented in several publications toward the end of his teaching. The teaching concept was widely accepted in professional circles and still forms the basis of freehand-drawing lessons in many places today. Hans Döllgast's enormous influence on the »Munich drawing school« is also expressed in the unofficial, but common, designation as »Döllgast School«. It is one of the privileges of the »Munich School«, that until today we can still refer to his teaching methods from the drawing textbooks, which are still in use and form a fundamental foundation for freehand-drawing.

Döllgast's work now dates back more than 60 years. Currently, freehand-drawing and sketching play a rather subordinate role in the architects' timetable. Compared to the considered period of the 150 years of existence of the »Munich School", today's teaching is subject to completely different conditions and has inevitably changed considerably. The digital turn from the 1990s onwards has finally made freehand-drawing in architecture an exception. In many other universities, the unrestricted belief in progress based on digital possibilities even led to the discontinuation of analogue drawing lessons, resulting in an irretrievable loss of knowledge. In Munich, at least one small compulsory subject was left as it was, through which teaching methods and »know-how « were passed on more or less continuously up to the present day. The fact that hand-drawing has been largely detached from the teaching process raises the urgent question among drawing teachers, including the author, as to what role freehand-drawing can currently play in the creative process of architecture. After all, university drawing classes should not be satisfied with the sole aim of enabling students to produce hand-drawings. It should be just as clear for what purpose this ability can

2 Hans Döllgast (1891-1974) studied architecture at the Technical University of Munich under Paul Pfann, Joseph Bühlmann, and Friedrich von Thiersch. He worked with Richard Riemerschmid (Munich-Pasing) and Peter Behrens (Vienna), from whose master class he graduated. He taught at the Technical University of Munich between 1929 and 1956, thus influencing an entire generation of architects through his drawing teaching. 
be used. At best, the teaching method should initialize exemplary work-processes with the freehand-sketch, and in this way, assign practical uses to the tool. The positioning of teaching hand-drawings in the constantly changing architectural education is a current challenge which is ultimately decisive for the lasting success of analogue drawing.

Now, one could of course ask why it should make sense for a drawing teacher to deal with the history of his or her own subject, its didactics and methods, in a time where there is obviously no lack of problems. In addition, the period under investigation for the »Munich School of Architectural Drawing « covers the enormous period of more than 150 years and was held in epochs long past, which are now difficult to access. However, it was precisely the unbroken continuity of teaching and the oral transfer of knowledge in the "Munich School« that demanded an introduction to the history and especially to the genesis of the teaching method, enabling one to place the knowledge and know-how in a context of origin and thus understand the intended purpose. Furthermore, the innumerable and changing possibilities of the occupation-specific use of drawing and sketching were exploited in this research, which not only sets the archival drawing collections into the context of their use and thus explains them plausibly, but can also contain core concepts that aid current handling. Furthermore, the story could help us gain clarity about controversial methodological concepts in order to finally be able to include them in currently discussed architectural teaching practices.

The basic precondition and starting point for the research concerned the knowledge of the orally transmitted, traditional form of today's teaching of the »Munich School«; its lessons, method, and the special handling of the projection rules. Without this knowledge and without the knowledge of the urgent challenges facing contemporary teaching, the research question could not have pursued this specific intention.

In order to reconstruct the teaching methods, numerous archival documents were drawn upon, which, when put together in an orderly fashion, finally formed a comprehensible overall picture of the »Munich School«. The teachers' estates and other archival materials are in the architectural collection of the Technical University of Munich, the Städtische Galerie im Lenbachhaus, the Munich City Museum and in private collections.

The basic material can be summarized in the following main groups: The manuscripts for lectures and drawing exercises, the documented blackboard drawings, sketchbooks from the classroom (some of which also have 
private entries), lecture notes, and publications or scripts for training. These five main groups have never been systematically recorded, scientifically evaluated nor put into context. All of the material had to be digitized and catalogued first. The time required to organize the data took about 80 percent of the time. The results of the archival research were presented in an annotated Catalogue of Sketchbooks and Sheet-Collections, the Biographies of Drawing Teachers, and the Course Catalogue in chronological order and initially formed a fundamental basis of data in the context of this work, but can also be used for future research projects. Indeed, the archive holdings are continually growing. In particular, bequests from the middle to the end of the 20 th century are increasingly being added to the collection. In a research project that aims to depict a factual situation up to the present day, it is inevitable that extensive additions from the recent past must be factored in, which could not be taken into account when the work was undertaken.

In order to bring the Munich material into a broader context, drawingpedagogical instructions or drawing-books, ${ }^{3}$ which have been developed in Central Europe from around 1500 until today, were recorded according to lesson topics in order to determine whether the »Munich School used established schemes or behaved autonomously. In addition, a list of architectural office activities was compiled in order to assign entries made by Munich drawing teachers in their sketchbooks to design projects.

With an observation period of more than 150 years, it should be clear that a complete compilation of all available information was difficult to achieve. Above all, only the most essential aspects regarding biographical information, political backgrounds, and architectural theoretical positions were examined and were only incorporated to the extent that they seemed significant for a description of the Munich drawing-lessons.

The compilation of the material suggested a chronological sequence of developmental steps to the structure of the research work. Paradigmatically,

3 From about 1500 onwards, the genre of so-called »drawing-books« and »printed drawingcollections (for copying) came into being, which were aimed at laymen as well as professional users. They were written by practitioners and reflect the level of knowledge and the basic approach of their respective epochs. Extremely influential were: Alberti's Della Pittura published 1436, Bergmann's Schule des Zeichners published 1855, Buchotte's Les Régles du Dessein published 1743, Burg's Geometrische Zeichenkunst published 1845, De Vries' Perspective published 1604, Dupain de Montesson's Science des Ombres published 1786, Lairess's Crundlegung zur Zeichenkunst published 1727, Monges's Céometrie Descriptive published 1820, and many more. 
the structures of the relevant, thoroughly astute, and profound scientific publications on the subject of drawing or even drawing lessons from the field of art history served as models for the methodical compilation of the material. The applied and long-established methods are capable of precisely describing drawing inventories: from the autographic description of style to the analysis of the basic perspective construction.

Similar to the methods used in art history, the development of the Munich drawing school could also be uncovered on the basis of all the evidence in order to finally retell a plausible story.

\section{The Architectural View}

There are, however, other levels of observation of drawings that derive from the special architectural view and the traditional use of drawings. It is the ability of design that enables a special reading of drawings and directs the focus to the content presented. No other discipline is able to describe the various facets of a design process with the tool of drawing and able to trace the stages of the draftsman.

This also applies to drawing lessons, which are primarily a part of the architectural curriculum at educational institutions. This raises questions which are still relevant today in the context of drawing/architecture lessons: Why is this particular architecture being drawn? Why is this particular situation interesting? Even in the art-educational documents of the earlymodern period, it is stated that drawing triggers processes of cognition. In the archives of the Munich School, there are series of study sheets that deal with the basic principles of architectural design. The architect is familiar with these topics and the difficulties involved: the joining of materials, for example, or the superimposition of different principles of order. The architect can not only name the principles, but can also recognize the importance, peculiarity or humor.

In the written documents of the archives, the drawing teachers finally name, often in a completely different context, their understanding of architectural-spatial situations. For example, a motif is not drawn because it is particularly picturesque, but because it offers complex spatial sequences and zones of transition.

Two areas of investigation therefore play an important role in the compilation of this research work: 
On the one hand, the purely graphic training, the subjects and lessons of which have been presented in drawing textbooks, that encompass the aim of achieving a sophisticated and natural approach to drawing. On the other hand, however, drawing is also a means to an end in the teaching of architecture, with all of the aspects that appear in the basic training of architects. With relevant cross-references, this approach generates typical questions in which the knowledge and experience of a designing architect is the prerequisite for the conception of a research project that aims to advance and enrich the current work on architecture.

For me, as a drawing teacher, it was important to extend the research to the point where the fundamental principles in the conception of drawing lessons could be identified and that the findings from the archives could be used as a stimulus and method for future lessons.

\section{References}

Michaelsen, Sven (2018): »Fast die ganze Welt hat sich der Diktatur der Marktwirtschaft unterworfen. Interview von Sven Michaelsen mit Rem Koolhaas«, in: Süddeutsche Zeitung Magazin, 20/2018, May 18, 2018.
Vasari, Giorgio (2012 [1550]): Alessandro Nova (ed.), Einführung in die Künste der Architektur, Bildhauerei und Malerei, 2nd corrected edition, Berlin: Verlag Klaus Wagenbach. 